\title{
Output voltage characteristic in system lighting road based on heat pipe and thermoelectric
}

\author{
Wayan Nata Septiadi ${ }^{1,2, *}$, Made Ricki Murti ${ }^{1,2}$, Arliyandi $^{1,2,3)}$, I G. A. Pristha Arvikadewi ${ }^{1,2,3)}$, I Putu Yuda Pramana Putra ${ }^{4)}$ \\ ${ }^{1}$ Department of Mechanical Engineering Udayana University, Kampus Bukit Jimbaran Badung-Bali, Indonesia \\ ${ }^{2}$ Heat Transfer Laboratory Department of Mechanical Engineering Udayana University \\ ${ }^{3}$ Bachelor Programme Student of Department of Mechanical Engineering, Udayana University \\ ${ }^{4}$ Department of Electrical Engineering Udayana University, Kampus Bukit Jimbaran Badung-Bali, Indonesia
}

\begin{abstract}
A novel design of a thermal management pavement system is introduced in this paper. The basic concept behind this design is a utilize of waste heat from asphalt pavement have as a base a heat pipe and thermoelectric for energy of street lighting. In this system, output voltage is influenced by difference in temperature between hot side and cold side of thermoelectric. The intensity of solar radiation at hourly is variant, so the resulting of output voltage fluctuated. The research method by field testing direct exposed solar radiation on the variation time at $09.00 ; 10.00 ; 11.00 ; 12.00 ; 13.00 ; 14.00 ; 15.00 ; 16.00$ Indonesia Central Standard Time. The data of this research are surface temperature of asphalt pavement, difference in temperature between hot side and cold side of thermoelectric, and output voltage of system. The analysis process by quantitative experimental. In this research, the output voltage increased from 09.00 until 13.00, and after that time the output voltage decreased.
\end{abstract}

\section{Introduction}

Road infrastructure energy harvesting technologies are a new research area that encompasses technologies that collect the wasted energy occurred in road space such as pavements, external space and store it for later use [1]. Asphalt pavements tend to absorb solar energy and accumulate heat which results in several negative effects, and contribute to the urban heat-island effect, plastic deformation of pavements, and aging of asphalt materials [2]. Asphalt pavement has absorptivity (a) and emissivity value $(\varepsilon)$ i.e. 0.93 to 0.9 [3]. One part of asphalt pavement can still save energy even though the sun has set in a certain period of time[4].

Datta et al. [5] developing a thermoelectric energy harvesting prototype for asphalt pavement roadways. The proposed prototype collects heat energy from the pavement surface and transfers it using a copper plate to a TEG module embedded into the subgrade at the edge of the pavement shoulder. The results suggest that the 64 $\mathrm{mm} \times 64 \mathrm{~mm}$ TEG prototype is capable of generating an average of $10 \mathrm{~mW}$ of electric power continuously over a period of 8 hours, for the conditions in lower latitudes such as South Texas, the asphalt pavement surface temperature in the summer as high as $55^{\circ} \mathrm{C}$ due to solar radiation. Soil temperatures below the pavement, however, are roughly constant (i.e., $27^{\circ} \mathrm{C}$ to $33^{\circ} \mathrm{C}$ ) at relatively shallow depths $(15 \mathrm{~cm})$. Scaling up this prototype using multiple thermoelectric elements could generate sufficient electricity to sustainably power LED lights for signage, illumination or instrumentation.
Jiang et al. [6] developing a set of road thermoelectric generator system (RTGS), which can generate electricity when there is a temperature difference between the road surface and ambient air. The modules convert heat absorbed in asphalt pavements using vapor chamber. Results showed that the output voltage of RTEGS was about $0.4 \mathrm{~V}$ by asphalt mixture slab $(300 \mathrm{~mm} \times 300 \mathrm{~mm}$ by size $)$ when the temperature difference between the road surface and ambient air was $15^{\circ} \mathrm{C}$ in winter. While in summer, the output voltage was about $0.6-0.7 \mathrm{~V}$, with a temperature difference of $25^{\circ} \mathrm{C}$ $-30{ }^{\circ} \mathrm{C}$. This means that some $160 \mathrm{kWh}$ of energy can be obtained in 8 hours from a road of $1 \mathrm{~km}$ in length and $10 \mathrm{~m}$ in width. For asphalt pavement in tropical and subtropical regions, the large temperature difference would be more suitable for RTEGS.

The use of heat energy into electrical energy is being done by using thermoelectrics. Thermoelectric is an electronic device which is a series of semiconductor materials using the principle of the Seebeck effect [7]. Thermoelectrics use different temperatures between the other side with the hot side. The greater the temperature difference that is formed, the greater the voltage generated from the thermoelectric circuit [8]. Some of the utilization of heat pipes carried out by Putra, Septiadi, Espinosa and Orr B [9-13] such as the use of exhaust heat from motor vehicles into electrical energy, the use of heat pipes and thermoelectrics such as coolants on vaccine vaccines and the use of heat pipes as heat exchangers or cooling systems on the CPU.

\footnotetext{
* Corresponding author: wayan.nata@gmail.com
} 
A novel design of a thermal management pavement system is introduced in this paper. The basic concept behind this design is a utility of waste heat from asphalt pavement have as a base a heat pipe and thermoelectric for the energy of street lighting. The output voltage of this system is influenced by the difference in temperature between the cold side and the hot side of thermoelectric. The heat source of the thermoelectric thermal side is obtained from waste heat on asphalt pavement, which is transferred using heat pipes. While the cold side of thermoelectric is determined by convection heat transfer from the heat sink to air environment. This resulted is output voltage was fluctuating at any time. So this research is intended to know the characteristic of the output voltage.

\section{Methodology}

The research method by field testing direct exposed solar radiation and the analysis process by quantitative experimental. The data of this research is to find difference in temperature between hot side and cold side of thermoelectric and output voltage of system. The power generation system based on heat pipe and thermoelectric designed with Four straight heat pipe units $\varnothing 10 \times 700 \mathrm{~mm}$, Qmax $350 \mathrm{~W}$, eight thermoelectric generator modules SP 184827145 SA, one MPPT unit Tracer1210A and asphalt pavement specimen 40 × 40 $\mathrm{cm}$. Experimental processing was performed with several thermocouples placed on the part of the specimen of asphalt pavement, in hot side, and cold side of thermoelectric. Temperature read by the sensor will be distributed to computer system using modul NI 9123 and C-DAQ 9174. Data is view by using NI LabView 2017 software. The output voltage and electric current is read by multimeter (Fig. 3.1). Variation of data retrieval time is at $09.00 ; 10.00 ; 11.00 ; 12.00 ; 13.00 ; 14.00 ; 15.00$; 16.00 Indonesia Central Standard Time.

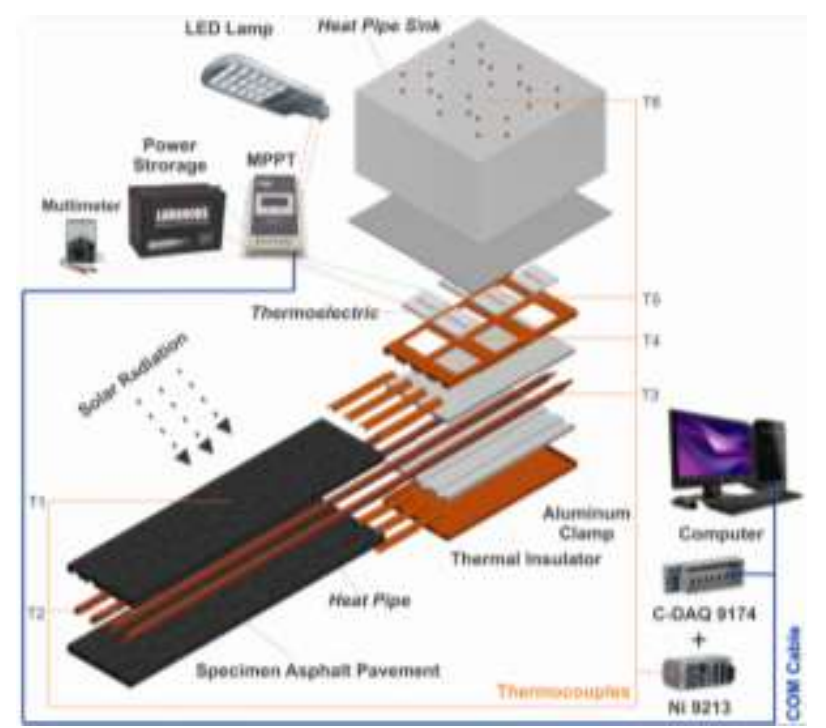

Fig. 1. Experimental set-up of heat pipe and thermoelectric power generation

\section{Result and Discussion}

The output voltage generate by thermoelectric depends on difference in temperature between hot side and cold side thermoelectric. Measurement of temperature difference between hot side and cold side data get results as in table 1. Asphalt surface temperature affects the heat pipe temperature of the evaporator and condenser parts. From the table above shows that the asphalt drying temperature, heat pipe temperature of the evaporator and condenser has a small difference. This indicates that the heat absorption rate by the heat pipe has a good performance. The thermoelectric circuit is very dependent on the difference temperature generated by the cold side and hot side of thermoelectric. Figure 2 becomes different the temperature formed at heating at 09: 00 a.m, ad 12:00 a.m.

Table 1. Output voltage and current of thermoelectric module

\begin{tabular}{|c|c|c|c|c|c|c|}
\hline \multirow{2}{*}{ Time } & \multirow{2}{*}{$\begin{array}{c}\mathrm{T}_{\text {surface }} \\
\text { Asphalt } \\
\text { pavement }\left({ }^{\circ} \mathrm{C}\right)\end{array}$} & \multirow{2}{*}{$\Delta \mathrm{T}_{\text {hermoelectric }}\left({ }^{\circ} \mathrm{C}\right)$} & \multicolumn{2}{|c|}{ Termoelectric Output } & \multicolumn{2}{|c|}{ MPPT Output } \\
\cline { 4 - 7 } & & Voltage $(\mathrm{V})$ & $\begin{array}{c}\text { Current } \\
(\mathrm{A})\end{array}$ & Voltage (V) & Current (A) \\
\hline $9: 00$ & 72.3 & 38.7 & 7.8 & 3.04 & 14.4 & 1.65 \\
\hline $10: 00$ & 78.4 & 40.6 & 9.3 & 3.61 & 14.4 & 2.33 \\
\hline $11: 00$ & 80.2 & 45.9 & 10.2 & 4.04 & 14.4 & 2.86 \\
\hline $12: 00$ & 84.6 & 49.3 & 11.9 & 4.41 & 14.4 & 3.64 \\
\hline $13: 00$ & 83.8 & 50.2 & 13.4 & 5.34 & 14.4 & 4.97 \\
\hline $14: 00$ & 83.1 & 49.1 & 11.6 & 4.35 & 14.4 & 3.50 \\
\hline $15: 00$ & 82.3 & 48.7 & 11.4 & 4.21 & 14.4 & 3.33 \\
\hline $16: 00$ & 77.6 & 42.7 & 9.9 & 3.77 & 14.4 & 2.59 \\
\hline
\end{tabular}


Different temperature the highest is formed on thermoelectric heating at 1:00 p.m. it reached 50.2OC and different temperatures which are formed at 4:00 p.m. not significant losses compared with 12:00 a.m and 01:00 p.m like that shown in figure 3.

In the overall system heat Asphalt is delivered to the thermoelectric generator to produce 23.7 watts up to 71.6 watts with an area of asphalt heat absorption area $40 \mathrm{~cm} \mathrm{x}$ $40 \mathrm{~cm}$. This is enough to provide for Attachment of the power needed for the system toll road lighting with the use of LED lights. Thermoelectric generator system with a system heat conductor in the form of this heat pipe will generate heat on the hot side thermoelectric and the cooling system which is on the cold side will form the temperature difference through the effect Seebeck will be converted to a voltage. The voltage connected to the MPPT circuit will condition the voltage and current strength on optimum position so that it is charging to the system storage will be more optimal.

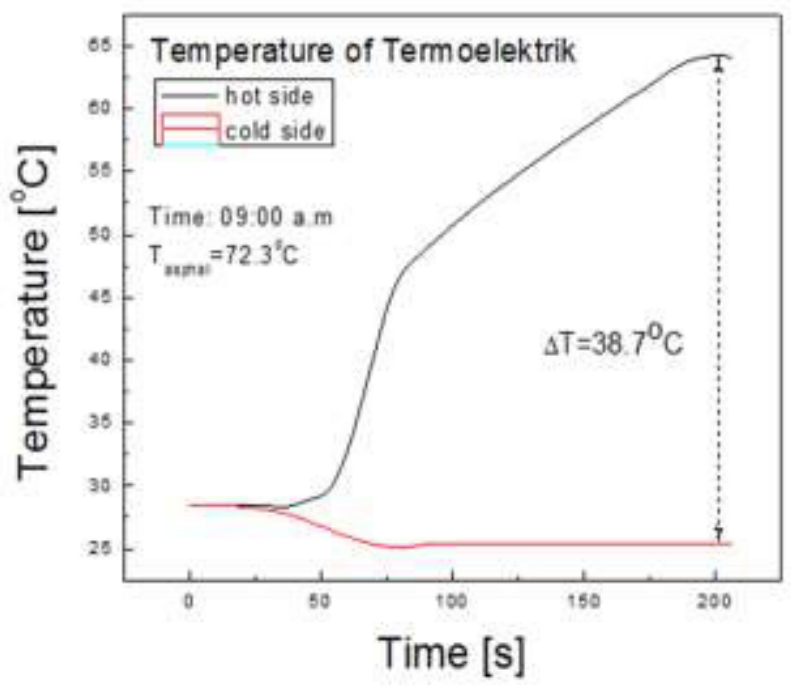

(a)

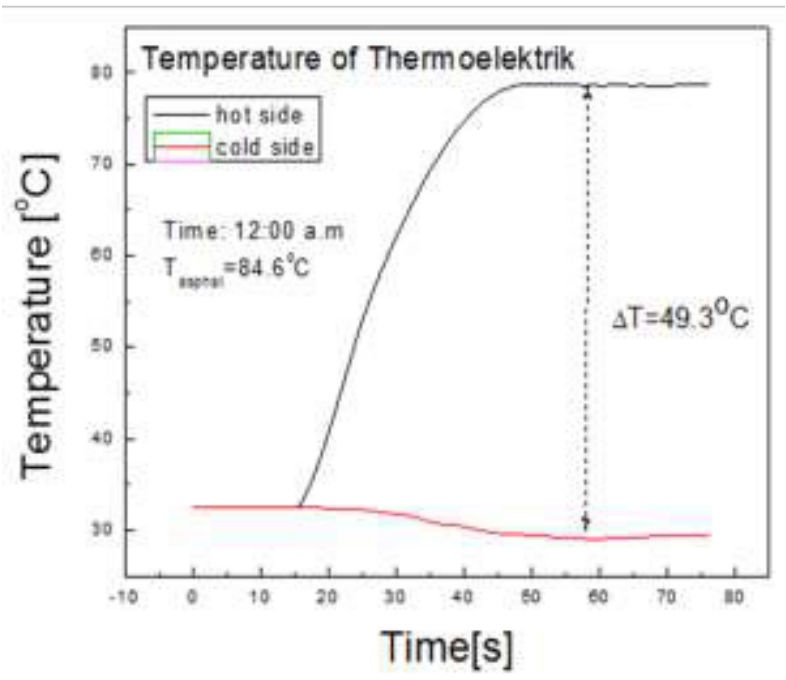

(b)

Fig. 2. Difference temperature of thermoelectric modules (a) at 09:00 a.m, (b) at 12:00 a.m

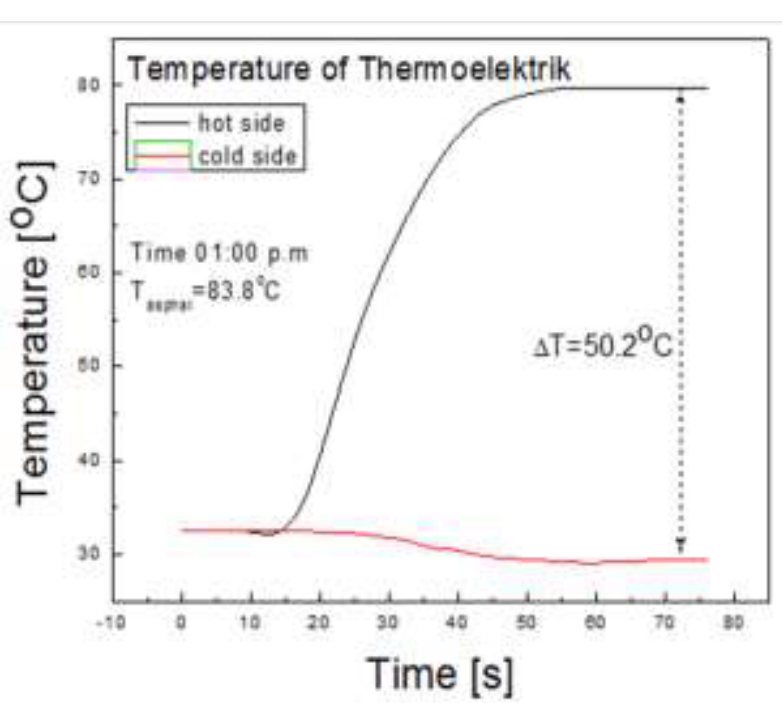

(a)

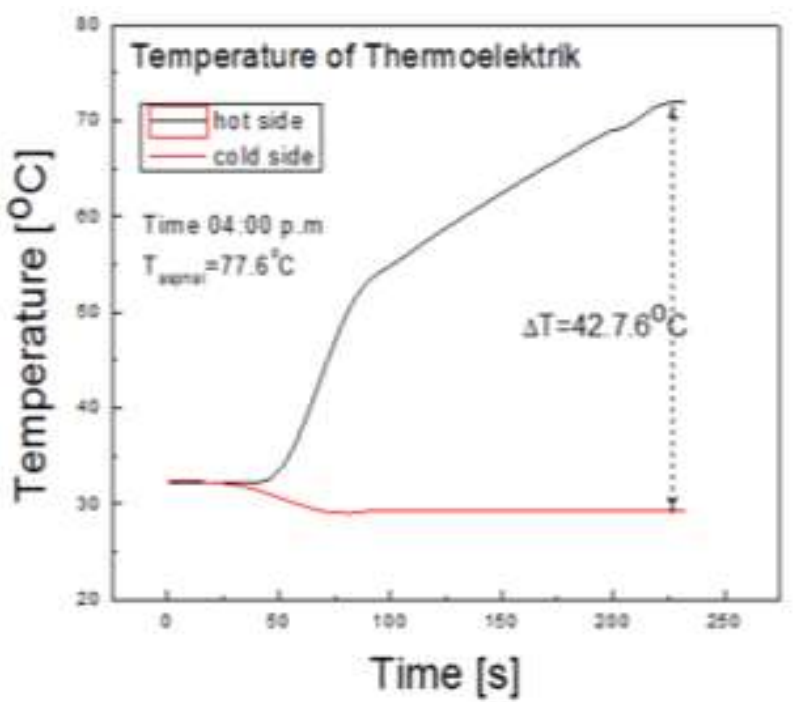

(b)

Fig. 3. Difference temperature of thermoelectric modules (a) at 01:00 p.m, (b) at 04:00 p.m

MPPT directs the voltage generated by the thermoelectric to the optimal voltage where the amount of power produced remains the same but the voltage is optimized at $\geq 14.4$ Volts so that the output after MPPT leading to the current battery is adjusted accordingly. Based on the maximum current strength of 4.97 Ampere using a battery of 12 Volts and $100 \mathrm{Ah}$, the predicted power of 1200 Watt will be charged to the battery for 18.72 hours of charging time. This allows for 48 watts and 120 Watts of highway lighting, where the power charged in the battery is sufficient and there is still residual power for lighting for 12 hours. If an average power of 3.36 Ampere is used then a battery capacity of 12 Volts and 100 Ah takes 14.88 hours to charge 600 Watts. It also still meets the use of 48 Watt toll road lighting operating for 12 hours.

\footnotetext{
* Corresponding author: wayan.nata@gmail.com
} 


\section{Conclusion}

From the test results, it can be concluded that the asphalt temperature is very capable to heat the thermoelectric heat side so that the temperature difference between the hot side and the thermoelectric cold side can be formed. The biggest temperature difference for the $1600 \mathrm{~cm} 2$ asphalt heat absorption area occurred at 1:00 p.m. with a temperature difference of $50.2 \mathrm{oC}$. Maximum power that can be produced is 71.6 watts. To increase the output power of the thermoelectric can be done by increasing the number of thermoelectric circuits and increasing the heat absorption area by a straight heat pipe

\section{References}

1. Lee J, Lim C, Kim D, Kwon S. Implementation of Thermoelectric Effects to Road Facilities. IRF Examiner 8:1-6 (2015).

2. Jiang W, Xiao J, Yuan D, Lu H, Xu S, Huang Y. Design and Experiment of Thermoelectric Asphalt Pavements with Power-Generation and Temperatur-Reduction Functions. Energy and Buildings 169:39-47(2018).

3. Bobes-Jesus V, Pascual-Muñoz P, Castro-Fresno D, Rodriguez-Hernandez J. Asphalt Solar Collectors : A Literature Review. Applied Energy 102:962-970 (2013).

4. Sheeba JB and Rohini AK. Structural and Thermal Analysis of Asphalt Solar Collector Using Finite Element Method; Journal of Energy (2014).

5. Datta U, Dessouky S, Papagiannakis AT, Harvesting of Thermoelectric Energy from Asphalt Pavements. Transportation Research Record: Journal of the Transportation Research Board 1222 (2017)

6. Jiang W, Yuan D, Xu S, Hu H, Xiao J, Sha A, Huang Y. Energy Harvesting from Asphalt Pavement using Thermoelectric Technology. Applied Energy 205:941-950 (2017).

7. Putra, Nandy, Iskandar, Ferdiansyah N.Performance Of Thermoelectric Module and Heat Pipe On A Vaccine Carrier Box, 7th International Conference on Heat Transfer, Fluid Mechanics and Thermodynamics, , Antalya, Turkey 19-21 (2010).

8. Nandy Putra, Yanuar, Ferdiansyah N.Iskandar, Application of nanofluids to a heat pipe liquid-lock and the thermoelectric cooling of electronic equipment,Experimental Thermal and Fluid Science 35 1274-1281 (2011).

9. Espinosa N, Lazard M, Aixala L and Scherrer H. Modeling a thermoelectric generator applied to diesel automotive heat recovery J. Electron. Mater. 39 1446-55 2010.

10. Orr B, Akbarzadeh A and Lappas P. Predicting the performance of a car exhaust heat recovery system that utilizes thermoelectric generators and heat pipes (2014).

11. Ahmad Hasnan, Nandy Putra, Wayan Nata Septiadi, Bambang Ariantara, Nasruddin A Abdullah. Vapor Chamber Utilization for Rapid Cooling in the Conventional Plastic Injection Molding Process. International Journal of Technology 4: 690-697 (2017).

12. Nandy Putra, Wayan Nata Septiadi, Gerry Julian, Ary Maulana, Ridho Irwansyah. An Experimental Study on Thermal Performance of Nano Fluids In Microchannel Heat Exchanger. International Journal of Technology (2013) 2: 167-177 (2013).

13. W.N. Septiadi, N. Putra, M. Juarsa, I.P.A Putra, R. Sahmur. Characteristics of Screen Mesh Wick Heat Pipe with Nano-fluid as Passive Cooling System. Atom Indonesia 1:39: 24-31(2013) 